\title{
Cadaveric spasm
}

\author{
Marcella F. Fierro
}

Accepted: 4 February 2013/Published online: 10 April 2013

(C) Springer Science+Business Media New York 2013

Do I believe in cadaveric spasm or accelerated or instantaneous rigor? Yes, but it occurs very rarely. Even those who dispute the concept acknowledge a few instances in which it might have occurred. For example, I can recollect seeing it three times in more than 30 years. All three cases had asphyxia as an important element in their deaths.

The first case was a smothered infant who was grasping the asphyxiating blanket enclosing him so tightly in front of his body that it could only be removed with great difficulty.

The second was in a young man who died in a supine position during a seizure. His face was flushed and exhibited florid petechia. His hands were fisted next to one another, symmetrically, high on his chest under his chin.

The third was a couple found drowned in a swimming pool. They were facing one another. Her right foot was placed on his flexed left knee and she was grasping his head as she pushed him down. He had his hands on her waist. They were grasping each other tightly when found and remained together as they were pulled from the pool.

These cases seemed to fit the criteria of (1) not having been moved from the position at death, (2) the positions in which they were recovered were not "physiologic" for a dead body, and (3) they were, at death, in a highly stressful situation likely preceded by at least a brief interval of struggle or intense muscular activity. Doubters may argue there were no witnesses to attest to instant rigidity but in the aforementioned cases it would seem that the onset of postmortem flaccidity, especially in the seizure and drowning cases would have resulted in the extremities relaxing in a different position. The drowning dyad would have been expected to float away from one another and the seizure victim's arms when loose to have migrated toward the sides of the body. There are credible challenges to the concept of cadaveric spasm when bodies are propped, in equipoise or in flexion as seen in fire or high heat situations. I would not dispute guns or blades grasped in hands. But there are those few difficult cases that are unexplained and must include serious consideration of cadaveric spasm as a forensic reality $[1,2]$.

\section{References}

1. Madea B. Cadaveric spasm. Forensic Sci Med Pathol. 2013. doi: 10.1007/s12024-012-9403-5.

2. Bedford PJ, Tsokos M. The occurrence of cadaveric spasm is a myth. Forensic Sci Med Pathol. 2012. doi:10.1007/s12024-0129391-5.
M. F. Fierro $(\square)$

Commonwealth of Virginia,

8702 Berwickshire Drive, Henrico, VA 23229-7833, USA

e-mail: marcella@fierroforensics.com 